\title{
Biografia e desempenho do docente: como melhorar a qualidade do ensino de história?
}

Bruno Bezerra Cavalcanti Godoi ${ }^{1}$.

\section{RESUMO}

Como melhorar a qualidade das escolas? Esse artigo procura mostrar a relação entre características pessoais e ação docente, com base em uma entrevista com um professor de História da rede pública e no exame da bibliografia recente sobre o tema. Com base nessa constatação, sugerem-se alterações na formação de professores com o objetivo de melhorar a qualidade de ensino.

Palarpss-chaves professor, prática docente, metodologia de ensino.

O professor pode melhorar a qualidade de sua anuação caso faça uma autocrítica de sua própria história de vida.

Esse trabalho foi motivado pela crise atual da educação brasileira, em que a sociedade está insatisfeita com os resultados cognitivos de sua escola², apesar do crescimento da titulação docente.

Face a esse problema, foram adotadas diferentes vertentes teóricas da pedagogia, como o construtivismo, o cognitivismo, o sócio-construtivismo e 0 behaviorismo por parte das Secretarias de Educação, mas sem resultados. Também surgiram métodos padronizados de ensino, tais quais o do Objetivo, Pitágoras e Dom Bosco. Mesmo assim, ainda não foi realizado o sonho comeniano de ensinar "tudo a todos".

É claro que encontra-se no plano político grande parte do problema educacional. O Brasil gastou entre $3,9 \%$ e 4,3\% do PIB, entre 1994 e 1999,

1 Professor da Secretaria de Estado da Educação de São Paulo e Mestrando em História na Universidade de São Paulo (USP).Email: bg_usp@hotmail.com.

2 Segundo a pesquisa publicada no jornal "O Globo", de 9 de setembro de 2003, apenas 25\% das pessoas entre 15 e 62 anos consegue compreender a mensagem de um texto longo e localizar informações dentro dele. $30 \%$ escreve palavras e identificar informações em frases curtas e 37 \% é capaz de escrever pequenos bilhetes. 
menos do que Argentina, Chile, Irlanda e da média da OECD 3 . Os salários dos professores são reconhecidamente baixos, da mesma forma que o capital cultural da maioria das famílias das classes C, D e E. Mesmo assim, uma autocrítica dos docentes acerca de sua própria atuação traz resultados positivos, uma vez que o trabalho docente tende a ter um forte caráter prático.

Para fins de convenção, neste artigo define-se qualidade de ensino como "capacidade de obter resultados positivos nas competências exigidas pelos Parâmetros Curriculares Nacionais". No caso de história, isso significa fazer os alunos desenvolver nos alunos a capacidade de avaliação crítica dos eventos passados, para então encadeá-los num contexto, fazer separações analíticas e estabelecer relações com tempos diferentes.

Claro que há inúmeras leituras sobre o que seria uma "boa escola", desde a puramente economicista de Gary Becker até a de transformação social de Paulo Freire. Infelizmente, devido ao escopo limitado desta pesquisa, fica-se restrito às próprias definições oficiais quanto ao papel a ser desempenhado pelo ensino.

Como fica evidente, tentou-se melhorar a qualidade da escola por intermédio de pesquisas que procuraram o "método perfeito" e por políticas públicas que incentivaram, a certificação de docentes. E existe uma crença de que ambas medidas falharam. Logo, é necessário buscar outras alternativas.

A literatura recente aposta na correlação entre o desempenho docente e a biografia deste. Segundo KNOWLES (1997, pág. 105), este é resultante da sua educação parental, da capacidade de solução de problemas, da representação pessoal da escola e da experiência como estudante da universidade e nos primeiros anos de atuação profissional.

\section{História de vida e o desempedo docente}

0 autor fez o estudo de caso de cinco professores, recentemente formados na universidade: Elizabeth, Dwayne, Cynthia, Mona e Kirsten.

Elizabeth, em seu primeiro mês, apresentou dificuldades. Ela já tinha ensinado religião num curso dominical ${ }^{4}$, em que os estudantes estavam interessados, já que eram cursos voluntários, ao contrário de uma escola regular.

Fonte: INEP, Gasto em Educação, pág. 1.

Escolas dominicais são cursos que ensinam conceitos e doutrinas religiosas. 
Além disso, Elizabeth tinha sido sempre uma aluna de notas altas, sempre tendo sucesso na escola. Porém, os percalços a fizeram acreditar que era um fracasso, pela primeira vez na vida, e a fez procurar aprovação nos seus pupilos que, obviamente, não obteve.

Perante a falta de disciplina, ela tornou seu curso cada vez mais estruturado e com um modo de ensino um pouco mais autoritário, com 0 objetivo de motivar os alunos, ainda que coercitivamente, e a não esperar um ambiente amigável.

Cynthia não se tornou professora. Ela era insegura demais para se impor perante 40 alunos hostis, sentia-se mais à vontade em pequenos grupos, era muito téorica e não apreciava a vida escolar.

Durante sua adolescência, Cynthia freqüentou uma escola de elite em que 0 mais importante era a posição social, não o conhecimento. Essa experiência marcou muito, fazendo-a não apreciar a vida na escola, em que ela entendia como "um local em que os professores não estão interessados, principalmente se forem excêntricos. Os professores eram injustos, colocavam a culpa nos outros, muito críticos, impacientes e insistentes na conformidade" (Knowles, 1997, p. 123).

Ela também acreditou que um bom professor era aquele capaz de dominar um suposto conhecimento técnico sobre como ministrar aulas. Azanha (1987, p. 7) mostrou que este saber não existe e Nóvoa (1995, p. 20) considera-o uma ilusão.

Já Dwayne também teve uma experiência difícil quando estudante da escola, pois era sempre considerado como um fracasso e expiou-o tardiamente, ao fazer uma pós-graduação em História Africana. Somente tornou-se professor aos 39 anos.

Mona provinha de uma zona rural, com formação parental rígida. Na sala de aula, seu comportamento refletia a origem social: utilizava métodos tradicionais, era autoritária, focando no aprendizado de conteúdos.

Segundo NÓVOA (1992, p. 45), a experiência desenvolvida pelo docente relaciona-se com o seu comportamento em sala de aula e com a aceitação de inovações metodológicas.

0 professor passa por diversos estágios ao longo de sua carreira:

SOBREVIVÊNCIA: 0 professor iniciante ainda está inseguro sobre seu 
desempenho e procura soluções para motivar os alunos e a ser compreendido. ESTABILIZAÇÃO: Aqui, já se conhece o comportamento do aluno e 0 profissional já se sente mais seguro.

A partir de então, o desenvolvimento profissional bifurca-se, de acordo com a sensação de realização pessoal com a profissão. Caso ele se sinta satisfeito, passa-se pelos seguintes estágios.

INOVAÇÃO: 0 docente procura novidades para 0 exercício das suas atividades, procura aperfeiçoar-se cada vez mais e faz militância sindical.

SERENIDADE: Aqui, os anos de trabalho fazem o comportamento da sala de aula tornar-se previsível e existe uma certa acomodação.

Caso esteja decepcionado com a atividade docente, passa-se pelas seguintes fases:

QUESTIONAMENTO: Coloca-se em questão a própria escolha profissional e se procuram alternativas, como participar do corpo dirigente escolar ou mesmo mudar totalmente de profissão.

CONSERVANTISMO: Recusa-se a mudança das práticas de ensino e desenvolve-se um certo saudosismo, pois, supostamente, as escolas eram melhores no passado, com alunos mais disciplinados.

Finalmente, quando o instrutor coloca-se perto da aposentadoria, há a fase do desinvestimento.

DESINVESTIMENTO: Quando o docente começa a priorizar os interesses pessoais, como bobbies e viagens, colocando a profissão em segundo plano, pois está próximo à aposentadoria.

Assim, como a pesquisa recente defende a proximidade entre 0 desempenho da sala de aula e a história pessoal do docente, procederemos a uma entrevista pessoal de um professor, com 0 intento de compreender como funciona esta relação, se biografia é fato importante ou não para a ação de instruir e, caso seja verdade, conceber novas políticas públicas e práticas escolares com o intento de melhorar a qualidade de ensino.

\section{Transcrição da entrevista}

Entrevistou-se um professor, com o objetivo de explorar a hipótese de que 
o desempenho docente relaciona-se com eventos biográficos e características pessoais. Prevê-se que observando ambas variáveis pode-se procurar compreender a ação de um professor e melhorar seu desempenho.

Para tal, entrevistou-se o professor Valmi Pereira Oliveira, Professor Titular de História na Prefeitura Municipal de São Paulo. A entrevista foi feita em sua casa particular, no dia 16 de abril de 2005, das 3:00 hs até as 5:00 hs. Esta foi cuidadosamente preparada, com o objetivo de obter a maior quantidade possível de informações relevantes para o progresso da pesquisa educacional.

Antes da conversa, foi lida a obra de Paul Thompson, A Voz do Passado e diversas recomendações dessa obra foram observadas: manter o entrevistado à vontade, faze-lo revelar a maior quantidade possivel de dados, preparar previamente as perguntas, evitar confrontos de opiniões e não lançar idéias pessoais do entrevistador: Para maiores informações, vide THOMPSON (1992, p. 190).

Qual a sua formação? Em que ano se formou?

Sou bacharel e licenciado em ciências sociais na Fundação Santo André, no ano de 1992, e em Letras-Português na USP, no ano de 2004. Fiz pós-graduação lato sensu em Sociologia e História do Trabalho, me formando em 1994.

\section{Ensina bá quanto tempo?}

Ensino há oito anos. Trabalhei inicialmente como professor contratado na rede estadual de São Paulo de 1997 a 2000 e, na Prefeitura de São Paulo, desde 2000 até 0 presente.

\section{Qual o seu método de ensino favorito?}

Método às vezes um pouco tradicional, por meio de aulas expositivas, em outros momentos, por formas diferentes, como análise de textos, filmes e teatro.

Por que você quis ser professor?

Porque eu era apaixonado por falar em público, de ensinar pessoas, de conversar. Eu fiquei muito motivado pelo professores no ensino médio de História, Sociologia e de Português (Literatura), que ensinavam muito bem.

Em que escola você ensina? Ela é pública ou privada? Em que séries? 
Trabalho na EMEF "Alexandre Vanucchi Leme", pública, municipal, da $5^{a}$. a $8^{a}$. série.

Qual (quais) as escolas de primeiro e segundo gran que você frequentou? Mudou muito de escola?

Da $1^{\mathrm{a}}$. à $4^{\mathrm{a}}$ série do Fundamental, estudei numa escola estadual em Minas Gerais, em Serra dos Aimorés. Mudei na $5^{a}$. série para uma escola na rede estadual de São Paulo e me transferi para outra escola, também estadual, na $8^{a}$. série do Fundamental, em que fiquei até completar o ensino médio.

\section{o que você achava da escola quando era adolescente?}

Gostava muito da experiência escolar e o ensino médio me fez decidir definitivamente por ensinar, principalmente pelos docentes de História, Sociologia e de Literatura.

A sua experiência como aluno de primeiro e segundo graus the deu uma idéia sobre como era ensinar história?

Sim, pois meus professores utilizavam métodos que eu considerava interessantes. Gostava das aulas expositivas, em que o professor explicava 0 livro didático, dos seminários, das dinâmicas de grupo e de que os professores utilizavam todos os espaços da escola.

Quanto à dinâmicas, tinha um professor de literatura que, na época da morte de Carlos Drummond de Andrade, nos mandou para uma sala escura, nos deitarmos e fazermos uma "conversação" com o referido poeta.

Você formou uma idéia sobre como ensinar enquanto era aluno da universidade?

Observava a atuação dos professores e procurava tirar exemplos positivos de negativos deles.

Existiam professores que humilhavam os alunos, chamando-os de "pobres" porque tinham de sair 10 minutos antes do término da aula para pegar o ônibus, ou então insultavam um aluno quando ele não sabia a resposta correta. Outros eram relapsos porque davam poucas aulas e faltavam com muita frequiência. 
Quanto a exemplos positivos, temos o prof. Antônio Medina (USP) que se comunicava de uma forma muito clara e esclarecia tudo acerca da matéria. Também tinha o Prof. João Adolfo Hansen (USP), que também era muito inteligente e nos contava não somente a matéria, mas todo o contexto relativo ao conteúdo.

Você exerceu alguma função que requeria falar em público antes de terminar a universidade?

Ministrei diversos cursos livres antes de trabalhar na universidade, em São Bernardo do Campo (SP). Primeiro, na Igreja Católica, em que ministrei um curso de formação social, mostrando os problemas sociais e como a Teologia da Libertação poderia contribuir para minora-los. Depois, ensinei um curso, no Sindicato dos Servidores Municipais de Santo André, sobre funcionamento do sindicato e da história dos trabalhadores. Finalmente, também dei cursos de política no Partido dos Trabalhadores (PT).

Nesses cursos, desenvolvi um pensamento claramente de esquerda. Além disso, procurava fazer as pessoas que assistiam ao curso saírem da zona de conforto, não se acostumarem com o nível cognitivo que possuíam, porque entendia que isto era necessário para a compreensão dos problemas sociais. Por exemplo, entender que o desemprego não é um fenômeno normal e natural. Instintivamente, estava tornando-me construtivista.

Como foram as suas primeiras experiências como professor? Fáceis ou dificeis?

Tive dificuldades como professor. Comecei a ensinar em 1993, logo depois da faculdade. Porém, de 93 a 96, eu desistia no primeiro mês. Sentia-me travado, com medo de enfrentar uma classe hostil. Estava à vontade para ministrar cursos livres, porque quem assiste a estes interessa-se pelo assunto, ao contrário de uma escola comum. Não sei, mas acho que preciso de uma psicanálise para entender o que ocorria comigo.

Contudo, eu tinha outra profissão. Fui funcionário de um centro comunitário na Prefeitura de Santo André e fui entrevistador numa agência da Prefeitura de Diadema. Esse conforto, de ter outro trabalho, me motivava a não enfrentar o medo de sala de aula. 
Como enfrentou as dificuldades iniciais como professor?

Tudo mudou em 1997, quando desisti do emprego público e peguei carga horária integral no estado. Agora, eu precisava viver de dar aulas. E isso me fez enfrentar as dificuldades o suficiente para durar no Estado.

\section{Quando foi que você definiu um estilo de dar aulas?}

Depois de um ano de ensino. Meus medos ficaram controláveis e senti-me mais à vontade com a sala de aula. Comecei a entender o ponto de vista do estudante e a lidar com aqueles que desafiam o professor e não fazem as atividades. Creio que o professor está sempre aprendendo a ensinar, com a experiência.

Uma coisa que eu vejo, porém, é o desinteresse, por parte dos funcionários do sistema educacional, pela sua própria formação. Muitas vezes, tornei-me líder informal, porque leio basiante e já tive situações em que eu sabia mais que o coordenador pedagógico.

\section{Como se sente quanto à carreira? Realizado ou não?}

Sinto-me feliz com o ensino. 0 que eu acho é que deveríamos ter salas de aula menos barulhentas.

Você procura métodos inovadores para a sala de aula? Alterou sua forma de ensinar ao longo da sua carreira?

Acredito que o professor está sempre em formação. Procuro sempre mudar meus métodos de ensino. Tenho agora um projeto de usar o cinema e o teatro na sala de aula.

Você faz militância sindical? Por quêe? Como foi sua experiência como militante sindical?

Sou representante de escola no SIMPEEM (Sindicato dos Professores do Ensino Municipal), eleito pelos professores. Participei de deliberações, reuniões constantes e mesmo de greves. Ultimamente tenho participado de uma campanha para que o atual prefeito, José Serra, não deixe a sala de informática sem professor, pois isso vem sendo cogitado devido ao ajuste fiscal. 


\section{Apontamentos sobre a entrevista}

Fica evidente, usando a metodologia proposta por NÓVOA (1995, p. 55 ), que Valmi Pereira coloca-se na fase mais produtiva e profícua de sua carreira, a fase militante, sendo possível prever que ele empenhar-se-á em melhorar cada vez mais a qualidade do seu ensino.

Ele não somente sente-se identificado pessoalmente com a profissão, como também se esforça para melhorar as condições da escola e procura formas inovadoras de instruir. Ele empenha-se em evitar que a sala de informática fique sem a presença de um professor, participa do movimento sindical e esteve envolvido em greves. Por outro lado, procura formas diferentes de ministrar a aula, tentando inclusive criar um projeto de ensino de história por via de cinema e teatro. E também passou pela fase de estabilização, já tendo domínio sobre como ministrar aulas expositivas.

0 autor deste artigo observou pessoalmente o trabalho de Valmi Pereira, quando no estágio da disciplina "Psicologia da Educação". Valmi procura quebrar o conteúdo em várias perguntas, as quais ele dita as respostas para que os alunos copiem no caderno. Enquanto vai ditando, ele explica o assunto. Além disso, há um esforço para que os alunos saiam de sua zona de conforto, com o objetivo de ampliar a capacidade de aprendizagem da mente destes, dentro das acepções construtivistas.

Mereceu atenção especial a preocupação com as experiências iniciais como docente, pois este é um período difícil da carreira, em que muitos deixam a profissão. Há um descompasso muito grande entre a formação universitária nas licenciaturas e a vida escolar, até mesmo pela excessiva dependência das características pessoais do docente nas práticas escolares, e não pela técnica.

Segue-se um período de crise, quando eles sentem que não estão no controle do ambiente de aprendizado da sala de aula e sentiram-se "incapazes de serem ouvidos pelos pupilos". (KNOWLES, 1997, p. 108)

Perante tais dificuldades iniciais, o professor jovem pode tomar, segundo os casos examinados em KNOWLES (1997, p. 127), duas alternativas: a- deixar a profissão ou b- procurar alternativas para resolver as dificuldades. 
Como já descrito nos estudos de caso, Cynthia abandonou definitivamente a profissão. Sua decisão foi tomada em razão da sua insegurança para falar em público, do medo de se impor e pelo seu desinteresse pessoal pela vida escolar.

Já Elizabeth tinha ensinado como ministrante de cursos religiosos na Alemanha, em que existia interesse por parte da platéia, sendo que sua dificuldade foi de lidar com a resistência dos alunos da escola regular, em que a freqüência é involuntária. Perante essa situação, ela procurou usar a assertividade e um certo autoritarismo como forma de motivar os alunos.

Como vimos, o entrevistado Valmi enfrentou problemas, no caso o desinteresse dos alunos em aprender, tal como Elizabeth. Apesar de já ter ministrado cursos livres no Partido dos Trabalhadores, no sindicato e na Igreja Católica, ele ficou surpreso com a indisciplina dos alunos. Perante essa situação, ele renunciou temporariamente. Somente após quatro tentativas, e tendo deixado um emprego público, que perdurou como professor. Precisando do trabalho, ele acabou por se auto-superar.

É claro que podem ser encontrados outras motivações de Valmi para ensinar. Ele sempre se interessou pela vida na escola, como Elizabeth. Cynthia, por exemplo, não se sentia à vontade.

Quanto ao comportamento em sala de aula, Valmi inspirou-se na sua experiência como aluno do fundamental e médio, pois usam-se ferramentas semelhantes: aulas expositivas, tirar o aluno da "zona de conforto", dinâmicas de grupo.

Também há modelos da universidade, principalmente negativos. Os mestres de atuação relapsa e os que humilhavam os pupilos foram bastante enfatizados por Valmi.

\section{Conclusão}

0 presente trabalho procurou correlacionar a biografia com a carreira docente, mostrando o caráter pessoal do desempenho docente. Conseqüientemente, torna-se difícil formar, avaliar, selecionar e aperfeiçoar professores. Alguém com desempenho excelente na licenciatura pode ser fraco ao ensinar na escola.

Tendo em mente esses resultados, é possível conceber algumas soluções 
para melhorar a qualidade do ensino. Seriam necessárias alterações em três níveis: a preparação individual do docente, as políticas públicas de educação e a própria pesquisa acadêmica.

Contudo, é preciso estar ciente do escopo desse trabalho. 0 presente paper não possui elevado rigor científico, fez somente uma entrevista e empregou uma bibliografia limitada. Tenho somente o propósito de lançar idéias e de chamar a atenção para a complexidade da dinâmica do aprendizado.

Contudo, é necessário alertar sobre determinadas práticas errôneas que poderiam emergir do modelo biográfico. Em primeiro lugar, de que os professores poderiam ser melhor selecionados segundo baterias psicométricas. Apesar de fazermos uma relação entre comportamento e desempenho, ela é complexa demais para permitir criar predições.

Um professor que teve uma educação parental repressora pode atuar tanto de forma autoritária quanto de forma liberal em sala de aula. Alguém que pareça introvertido conforme 0 teste Mayer-Briggs mesmo assim pode ser seguro de si e ensinar de forma satisfatória.

Também não se deve legitimar estagnação ou redução salarial para os professores, pois este já é baixo demais em relação ao elevado nível de formação, como observado por SCHWARTZMAN (1988, p. 4), o que pode trazer, no longo, prazo, uma queda do nível de preparação dos novos docentes e de qualidade acadêmica da escola.

Dados os baixos salários e o pouco prestígio do ensino como profissão, os cursos de pedagogia e as licenciaturas tendem a funcionar como segundas ou terceiras opções para estudantes que não conseguem entrar em carreiras mais prestigiosas e bem pagas, ou para professores de primeiro grau que querem subir profissionalmente, e que terminam, quando mais qualificados, por deixar as salas de aula. A maioria dos professores e técnicos em educação de primeiro grau do setor público obtém seus diplomas em estabelecimentos privados, de qualidade presumivelmente mais baixa do que as faculdades de filosofia e educação do setor público. Esta situação repercute dramaticamente na qualidade do ensino básico, e só poderia ser revertida por modificações profundas nos níveis salariais no reconhecimento público e social da função pedagógica, e também pela revalorização dos cursos de formação de professores nas universidades públicas. 


\section{Políticas Educacionais: Estágios e a Figura do Tutor.}

É necessária a alteração de práticas de formação inicial de professores, já que o desempenho docente altera-se muito conforme os eventos da sua vida privada e mesmo da educação parental.

Assim, cada iniciante deveria ter um tutor. Esse, um professor experimentado, procuraria ajudar o novato a lidar com as dificuldades da sala de aula e buscaria soluções em conjunto para elas, tornando menos difícil a transição da universidade para a atividade docente, que, como vimos, trata-se de um processo árduo.

A atividade de mentor tem um duplo benefício: motivar docentes os mais antigos, que já se encontram na fase de desinvestimento ou de conservantismo, a ainda manterem 0 interesse pela profissão.

Outra questão importante trata-se dos estágios de obseivação. Assumido que 0 professor aprende observando colegas mais experimentados, torna-se necessário que o jovem passe a fazer mais horas de estágio, se possível com diversos colegas. Ao observar diversas posturas em sala de aula, obtém-se conhecimento prático em práticas de ensino. Seria uma experiência interessante colocar professores da rede pública novatos a fazer horas de observação, semelhantes à dos estudantes de licenciaturas.

\section{Preparação individual dos docentes.}

Também é importante que o professor iniciante tenha contato com as dificuldades da sala de aula o mais cedo possível, se possível começando a ensinar ainda durante a formação universitária (graduação e pós-graduação). É recomendável que o aluno da licenciatura comece a trabalhar como professor ACT (admitido em caráter temporário), substituto, em supletivos e cursinhos comunitários, ou seja, situações de menor responsabilidade, para conhecer precocemente a realidade da sala de aula.

É necessário estar consciente de que o ensino não é seguir uma técnica definida. Além disso, ensinar no sistema escolar é muito diferente de exercer a mesma função em cursos livres, associações culturais, Igreja ou grupos menores, pois os sujeitos da primeira têm uma tendência a verem a freqüência à escola como um evento desagradável. 


\section{Mudanças na pedagogia: o professor como produtor de conhecimento.}

Ficou patente que é necessário alterar a pesquisa acadêmica na área de pedagogia, para centrar-se no professor e entender que este é o principal agente criador de conhecimento, e não agente passivo da pesquisa pedagógica.

Assim, a pedagogia tem o papel sistematizador do conhecimento. 0 saber educacional deve partir da observação do cotidiano escolar. A pedagogia, como ciência, pode tomar o empírico e criar conhecimentos e leis acerca da escola. E seria importante aceitar os mestres como pesquisadores de importância igual ao dos cientistas doutores.

Dever-se-ia conceber entidades não-universitárias que pesquisem sobre a escola, em que a experiência tenha valor equivalente ao saber acadêmico. Por exemplo, uma academia vinculada às Secretarias de Educação ou mesmo bolsas de pesquisa para docentes.

\section{Referências}

"Apenas 25\% dos Brasileiros têm Domínio Pleno da Leitura e da Escrita". In: 0 GLOBO: Rio de Janeiro, 9 de setembro de 2003.

AZANHA, José Mário Pires. Uma Reflexão sobre a Didática. Educação: alguns escritos. São Paulo: Companhia Editora Nacional, 1987.

BRASIL. INEP. Gasto em Educação. Disponível em bttp:///wwwwinep.gov.br. Consultada às 11:22 do dia 19 de outubro de 2005.

BRASIL. Secretaria de Educação Fundamental. Parâmetros Curriculares Nacionais: Terceiro e Quarto Ciclos do Ensino Fundamental de História. Brasilia: MEC/SEF, 1998. 108 p.

KNOWLES, J. Gary. Models for Understanding Pre-Service and Beginning Teacher's Biographies: Illustration from Case Studies. In: NEUMANN, Anna e PETERSON, Penelope. Learning from our Liwes: Women, Research and Autobiography in Education. New York: Teachers College Press, 1997. pp 99-152.

NÓVOA, Antônio. Os Professores e as Histórias da sua Vida. In: (org.)

Vidas de Professores. 2a. edição. Porto: Porto Editorial, 1995. pp 11-61. 
SCHWARTZMAN, Simon. Brazil: Opportunity and Crisis in Higher Education. Higher Education, no.1, 1988. pp 1-50.

THOMPSON, Paul. A Voz do Passado: História Oral. Rio de Janeiro: Paz de Terra, 1992. $385 \mathrm{p}$.

Agradecimentos: Ao Prof. Valmi Pereira Oliveira pela sua boa vontade em contribuir com dados para a pesquisa e à Profa. Dra. Dislane Zerbinatti Moraes (Faculdade de Educação - USP), pela orientação e motivação.

BIOGRAPHY AND CLASSROOM PRACTICES: HOW TO IMPROVE THE QUALITY OF HISTORY TEACHING?

\section{ABSTRACT}

How to get better quality public schools? This article correlates teaching quality with personal characteristics, based on an interview with a history teacher in the São Paulo Municipal school system and the latest literature about school practices. Based in these facts, changes are suggested in order to get greater quality in education.

Reywords: 'Teacher, classroom practices, history teaching. 